\title{
Gang membership and marijuana use among African American female adolescents in North Carolina
}

This article was published in the following Dove Press journal:

Substance Abuse and Rehabilitation

9 November 2015

Number of times this article has been viewed

\author{
Wendee MWechsberg ${ }^{1-4}$ \\ Irene A Doherty' \\ Felicia A Browne ${ }^{1,5}$ \\ Tracy L Kline' \\ Monique G Carry ${ }^{6}$ \\ Jerris L Raiford ${ }^{6}$ \\ Jeffrey $\mathrm{H}$ Herbst $^{6}$ \\ 'Substance Abuse Treatment \\ Evaluations and Interventions \\ Research Program, RTI International, \\ Research Triangle Park, ${ }^{2}$ Gillings \\ Global School of Public Health, \\ University of North Carolina, Chapel \\ Hill, ${ }^{3}$ Psychology in the Public Interest, \\ North Carolina State University, \\ Raleigh, ${ }^{4}$ Psychiatry and Behavioral \\ Sciences, School of Medicine, Duke \\ University, Durham, NC, ${ }^{5}$ Department \\ of Social and Behavioral Sciences, \\ Harvard School of Public Health, \\ Boston, MA, ${ }^{6}$ Division of HIV/AIDS \\ Prevention, National Center for HIV/ \\ AIDS, Viral Hepatitis, STD and TB \\ Prevention, US Centers for Disease \\ Control and Prevention, Atlanta, \\ GA, USA
}

Correspondence: Wendee M Wechsberg Substance Abuse Treatment Evaluations and Interventions Research Program, RTI International, 3040 East Cornwallis Road, Research Triangle Park,

NC 27709-2194, USA

$\mathrm{Fax}+19194855555$

Emailwmw@rti.org

\begin{abstract}
The southeastern US sustains the highest high school dropout rates, and gangs persist in underserved communities. African American female adolescents who drop out of school and are gang members are at substantial risk of exposure to severe violence, physical abuse, and sexual exploitation. In this study of 237 female African American adolescents 16-19 years of age from North Carolina who dropped out or considered dropping out, $11 \%$ were current or past gang members. Adolescents who reported gang membership began smoking marijuana at a mean age of 13, whereas those who reported no gang membership began at a mean age of 15 years $(P<0.001)$. The mean ages of first alcohol use were 14 years and 15 years for gang members and non-gang members, respectively $(P=0.04)$. Problem alcohol use was high in both groups: $40 \%$ and $65 \%$ for non-gang and gang members, respectively $(P=0.02)$. Controlling for frequent marijuana use and problem alcohol use, adolescents who reported gang membership were more likely than non-gang members to experience sexual abuse (odds ratio $[\mathrm{OR}]=2.60$, 95\% confidence interval $[\mathrm{CI}][1.06,6.40])$, experience physical abuse $(\mathrm{OR}=7.33,95 \% \mathrm{CI}[2.90$, 18.5]), report emotional abuse from their main partner ( $\mathrm{OR}=3.55,95 \% \mathrm{CI}[1.44,8.72])$, run away from home $(\mathrm{OR}=4.65,95 \% \mathrm{CI}[1.90,11.4])$, get arrested $(\mathrm{OR}=2.61,95 \% \mathrm{CI}[1.05,6.47])$, and report violence in their neighborhood including murder $(\mathrm{OR}=3.27,95 \% \mathrm{CI}[1.35,7.96])$ and fights with weapons (OR $=3.06,95 \%$ CI $[1.15,8.11]$ ). Gang members were less likely to receive emotional support ( $\mathrm{OR}=0.89,95 \% \mathrm{CI}[0.81,0.97])$. These findings reinforce the urgent need to reach young African American women in disadvantaged communities affiliated with gangs to address the complexity of context and interconnected risk behaviors.
\end{abstract}

Keywords: school dropouts, youth alcohol use, sexual abuse, physical abuse, violence, drug abuse

\section{Introduction}

Structural determinants in the southeastern US place African American women and female adolescents at heightened risk of poverty, victimization, substance use, and sexually transmitted infections (STIs) including HIV ${ }^{1-3}$ Geographical segregation, discrimination, and sentencing inequities in the justice system and widespread incarceration, low-quality education, and lack of economic opportunities drive entrenched poverty, dropping out of school, ${ }^{4}$ alcohol and substance abuse, violence, crime, and gang activity. Drug use, drug dealing, and gang and neighborhood violence become accepted norms that carry over to violence in sexual relationships. ${ }^{5}$ African American women and adolescents living in socially disorganized communities have partners who are drug dealers, gang members, or were previously incarcerated. ${ }^{6,7}$ Substance use, lack of power in relationships, and physical and emotional abuse and sexual coercion are inherently connected. ${ }^{8-10}$ 
Young African American women struggling in this environment may be more likely to use and abuse alcohol and other drugs. Some female youth may become involved with gangs through spending time with gang members (ie, affiliation) to joining gangs as more formal members. ${ }^{11}$ The lines between level of involvement through affiliation and membership are blurred, and may or may not entail committing crimes. ${ }^{12-14}$ Nonetheless, interaction with gang members among female adolescents poses an exacerbated risk of exposure to severe violence, physical abuse, and sexual exploitation..$^{11,13,15-19}$

National estimates of female gang involvement vary widely, due in part to what constitutes a gang and how or to what extent gang involvement is measured (ie, affiliation vs membership). ${ }^{12,20,21}$ The National Youth Gang Survey of local law enforcement agencies reports that $10 \%-11 \%$ of gang members were female, a consistent trend from 1998 through $2010 .{ }^{20}$ However, $\sim 25 \%$ of respondents provided no information about females, ${ }^{20}$ perhaps because male activity poses a greater threat to public safety and burden for law enforcement. In a recent review, Chesney-Lind reports that various youth surveys have estimated that $20 \%-46 \%$ of female adolescents report some form of gang involvement (belonging, member, affiliate).$^{21}$ North Carolina is one of the 16 states where juvenile gangs account for the majority of crimes in some jurisdictions, ${ }^{22}$ and national crime data from 2003 to 2008 indicate that Raleigh, NC, is ranked 16 among 33 cities with high mortality and homicide rates attributable to gang violence. ${ }^{23}$ Trends from the National Youth Gang Survey suggest that the level of gang street crime has remained steady over a decade, ${ }^{20}$ a trend supported by extensive literature dating back at least 20 years for various populations of girls and female teens at risk of gang involvement. A common finding across most studies is that gang membership or affiliation among females tends to be associated with the following: poverty; physical, sexual, and emotional abuse or victimization; ${ }^{15,24}$ running away from home; ${ }^{15,25}$ neighborhood violence; ${ }^{26}$ illegal behaviors; marijuana use; homelessness and lack of parental and family connection; and low grades in school and dropping out of school..$^{24,27-30}$

Although studies show that young women tend to join gangs in early adolescence and disengage in early adulthood (eg, they may become pregnant), ${ }^{31,32}$ the adverse long-term consequences to their well-being are profound. A longitudinal study of 808 fifth-graders from underserved neighborhoods in Seattle followed participants into adulthood. At 27-33 years of age, former male and female gang members were more likely to continue to engage in criminal activity or be incarcerated, fail to complete high school, receive welfare, report poor general and mental health, and suffer from alcohol and drug dependence or abuse. ${ }^{33}$

This cross-sectional analysis aimed to closely examine the variability of alcohol and drug use as it relates to gang membership in a sample of African American female adolescents from underserved neighborhoods in Raleigh and Durham, NC. The analysis uses the baseline data from a randomized trial $^{34}$ that tested the efficacy of an adapted evidence-based HIV behavioral intervention (the Young Women's CoOp) funded by the US Centers for Disease Control and Prevention (CDC). ${ }^{35}$ This sample comprised 237 African American female adolescents (16-19 years of age) who dropped out or considered dropping out of school, reported high-risk sexual behaviors, and used drugs or alcohol regularly. We investigated the association between the magnitude of alcohol and drug use and gang membership within the context of a population in which marijuana use is normalized. ${ }^{2}$ Because the sample was at high risk of many adverse health and behavioral outcomes (alcohol and drug use, STIs, pregnancy, victimization), we chose to examine the most extreme level of gang involvement, where participants self-identified as past or present gang members.

\section{Methods}

The study was conducted between May 2010 and October 2012 at two project sites located in the inner cities of Raleigh and Durham, NC. ${ }^{3}$ RTI International's Institutional Review Board (IRB) approved the study protocol; CDC investigators did not interact with study participants.

Eligibility criteria included self-identifying as female, African American or black, between 16 years and 19 years of age, reporting dropping out of school or thinking about dropping out of school, not having a high school diploma or a GED, engaging in heterosexual vaginal intercourse within the past 3 months, using alcohol or drugs in the past 3 months, and intending to remain in the area for the next 12 months.

Participants were recruited through street outreach with collaboration from local service organizations, churches, schools, local radio advertisements, Facebook marketing, and respondent referral with use of recruitment coupons. Outreach staff members visited venues frequented by the target population and approached adolescents who might be eligible and interested in being screened for the study. All young women who were screened, regardless of eligibility or interest, received a $\$ 5$ gift bag of hygiene items for their time. 
Baseline visits took place at the field sites where participants were rescreened and provided informed consent. Verbal and written informed consent, or assent if a minor, was obtained prior to any study activities. The IRB waived obtaining parental consent from minors because of the sensitive nature of the study eligibility criteria - admitting to substance abuse and sexual activity. We have conducted prior studies with this concern in mind for recruiting substanceusing adolescents. ${ }^{36,37}$ To further protect adolescents, we obtained a Certificate of Confidentiality from the CDC.

Participants provided a urine sample for rapid tests for pregnancy (New Choice) and recent drug use (Reditest from Redwood Toxicology Labs). The drug panel detected cocaine, methamphetamine, marijuana, methadone, ecstasy, opiates, oxycodone, phencyclidine, barbiturates, and benzodiazepines. The baseline questionnaire comprised interviewer- and self-administered questions for the sensitive topics using Computer-Assisted Self Interviewing. Participants received a $\$ 30$ incentive for the baseline visit. Participants also received $\$ 15$ for each of five eligible referrals who enrolled within the first 90 days of receiving coupons.

The study partnered with a local AIDS service organization that offered testing for HIV, gonorrhea, and chlamydia at the study sites twice a week. Agreeing to HIV/STI testing was not a requirement for study participation. Staff from the AIDS service organization collected a finger stick blood sample for rapid HIV testing (UniGold Rapid Test) and a urine specimen for chlamydia and gonorrhea testing. The AIDS organization arranged for treatment of youth who tested positive for HIV or STIs. All study participants received an exhaustive referral guide of social services available within their communities for other needs.

\section{Measures}

This cross-sectional analysis used self-reported data collected from the baseline questionnaire. The survey included several questions related to gang exposure (via boyfriends, family, gang-related neighborhood violence) and involvement including affiliation ("hanging out with gang members") and membership. Gang membership served as the outcome, and was assessed with the question, "Have you ever been a member of a gang?" The primary independent risk variables were alcohol and marijuana use. Although the study performed drug screening, the prevalence of self-reported marijuana use was higher than biologically detected. The questionnaire asked participants the number of days that they smoked marijuana during the past 90 days. Self-reporting smoking on at least 45 days of the past 90 days constituted frequent marijuana use. The instrument included questions from the Alcohol Use Disorders Identification Test (AUDIT), ${ }^{38}$ also with a recall period of 3 months. A lower threshold for classifying problem drinking was established to provide more suitable assessment for adolescent females. The measure of problem drinking or alcohol dependence for these adolescents was drinking at least two times per month and at least three drinks each time. We created a continuous measure of alcohol consumption using a combination of questions from the AUDIT by assigning a numeric code to each response and summing them using the following two questions: 1) "How often did you have a drink containing alcohol?" with response options of never, monthly or less, two to four times a month, two to three times a week, and four or more times a week; and 2) "When you drink alcohol, how many drinks do you typically have at one time?" with response options of one or two drinks, three or four drinks, five or six drinks, seven, eight, or nine drinks, and ten or more drinks. Self-reported hard drug use included use of cocaine, methamphetamine, ecstasy, opiates (including heroin), oxycodone, or other prescription medications.

Confounding variables included characteristics and behaviors often correlated with gang membership, gang affiliation, or some other form of gang involvement that included socioeconomic factors (food insecurity, ever being homeless), running away from home, sexual risks (at least two sex partners in the previous 30 days, condom use at last sex, and ever trading sex), past or present abuse, psychosocial measures (social support, emotional support, depression), illegal behaviors (self and peers), and perceived exposure to neighborhood violence. Participants were coded as runaways if they stated that running away was one of the reasons they dropped out of school or if they responded yes to the question, "During the past 3 months, have you run away from home?"

Abuse measures included history of sexual abuse and physical abuse and current emotional abuse from participants' main sex partner. The emotional abuse scale ranged from 0 to $14 .{ }^{39} \mathrm{On}$ the basis of the distribution, participants with a score $\geq 3$ were classified as experiencing emotional abuse. The instrument assessed perceived neighborhood violence $(\alpha=0.92)$ with a series of questions that asked if the respondent observed violent events (eg, murder, fights with weapons) resulting in a scale ranging from 0 to 36 .

The Center for Epidemiologic Studies Depression scale assessed depressive symptoms $(\alpha=0.70) .^{40}$ Using findings from focus groups and qualitative interviews, we developed two assessments to measure material support $(\alpha=0.81)$ and emotional support ( $\alpha=0.60$ ). The questionnaire asked, "When 
you need money and other things, how helpful is/are your ..." for 12 types of people such as boyfriends, parents, and friends (options included "not at all helpful", "somewhat helpful", and "a great deal helpful"). The scale for emotional support used the same series of types of people, "When you go to talk about a personal problem, how helpful is/are your ...". Internal consistency estimates were established using Cronbach's $\alpha$. Estimates of 0.60 are sufficient for initial item set use and associated analyses. ${ }^{41}$

\section{Data analyses}

We performed descriptive analyses to characterize the sample with respect to socioeconomic status, sexual behaviors, reproductive health, psychosocial measures, past physical and sexual abuse, and exposure to neighborhood violence. Descriptive statistics for alcohol and marijuana use patterns were computed to investigate the degree of excess use among gang members. To identify correlates of gang membership, the analysis included contingency tables and logistic regression models that treated gang membership as the outcome. Each regression model controlled for problem alcohol consumption and frequent marijuana use because the goal of the analysis is to identify factors that persisted to be correlated with gang membership in this already targeted high-risk sample. Multivariable models are inappropriate with these data because all of the factors could be correlated with gang involvement and each other. ${ }^{42}$ Furthermore, given the small size, multivariable models may produce spurious results. ${ }^{42}$

\section{Results}

Outreach workers screened $>500$ young African American women; approximately half were eligible, and 237 enrolled in the study. Almost two-thirds (64\%) of those enrolled had dropped out of school at least once. Most participants were below grade level for their age (65\%) independent of dropping out (Table 1). Among those who had ever dropped out of school, the most common reasons included having missed a lot of school (69\%), family issues (58\%), disliked school (55\%), lack of support from family (49\%), bad grades $(39 \%)$, and expulsion (33\%). Overall only $18 \%$ were currently employed, $22 \%$ reported food insecurity, and $27 \%$ reported ever being homeless (Table 1). The majority of participants (76\%) did not live with any male adults (father, stepfather, grandfather, uncle, mother's boyfriend), and 35\% lived in single-headed households with their mother. One-third of participants moved at least twice in the past 6 months.

Teen mothers were not uncommon, as $29 \%$ reported having children. A total of 95 (40\%) participants reported ever
Table I Characteristics of African American female adolescents who considered dropping out or dropped out of school, Raleigh and Durham, NC, 20I0-20I2

\begin{tabular}{lll}
\hline & $\mathbf{n}$ & $\%$ \\
\hline Total & 237 & 100 \\
Demographics & & \\
Age, mean (SD) & $17.6(1.02)$ \\
Below grade level & 154 & 65 \\
Currently employed & 43 & 18 \\
Food insecurity & $5 \mathrm{I}$ & 22 \\
Ever homeless & 64 & 27 \\
Ever arrested & 80 & 34 \\
Live in single-headed household with mother & 83 & 35 \\
No male adult in household & 180 & 76 \\
Moved at least two times in past 6 months & 76 & 32 \\
Reproductive health & & \\
Ever given birth & 69 & 29 \\
Ever diagnosed with STI & 95 & 40 \\
$\quad$ Within past 6 months & 30 & 32 \\
Obtained STI test in study & 81 & 34 \\
$\quad$ Tested positive for STI & 23 & 28 \\
Exposure to gangs & & \\
Gangs in neighborhood & 132 & 57 \\
Know gang members & 225 & 95 \\
Hang out with gang members & 123 & 52 \\
Family members in gang & 167 & 70 \\
Witness gang fights & 92 & 39 \\
Ever had sex partner in gang & 165 & 73 \\
Ever member of a gang & 26 & 11 \\
\hline Abbrevatons: SD, sand & & \\
\hline
\end{tabular}

Abbreviations: SD, standard deviation; STI, sexually transmitted infection.

been diagnosed with an STI, and 32\% of those who had ever received a diagnosis had their most recent diagnosis in the past 6 months. Although only one-third of the sample received an STI test as part of the study, the prevalence of testing positive for chlamydia or gonorrhea or both was high (28\%).

The sample reported extensive exposure to gangs (Table 1). Nearly all of the young women knew someone in a gang (95\%), 57\% reported gangs in their neighborhoods, $52 \%$ reported gang affiliation (ie, hanging out with gang members), $70 \%$ had a member of their family in a gang, $39 \%$ reported witnessing gang fights, and $73 \%$ ever had a sex partner who joined a gang. A total of 26 participants (11\%) reported gang membership (current or in the past); all of these participants reported that a relative had been in a gang.

\section{Marijuana use}

The ages that young women smoked marijuana for the first time were markedly different by history of gang membership (Table 2). Adolescents who reported gang membership smoked the first time at a mean age of 12.9, whereas the mean age of those without gang membership 
Table 2 Patterns of alcohol and marijuana use by gang membership among African American female adolescents, Raleigh and Durham, NC, 2010-2012 ( $\mathrm{N}=237)$

\begin{tabular}{|c|c|c|c|c|c|}
\hline & \multicolumn{4}{|c|}{ Gang member - ever } & \multirow[t]{3}{*}{$P$-value } \\
\hline & \multicolumn{2}{|l|}{ No } & \multicolumn{2}{|c|}{ Yes } & \\
\hline & $\mathbf{N}$ & $\%$ & $\mathbf{N}$ & $\%$ & \\
\hline \multicolumn{6}{|l|}{ Marijuana use } \\
\hline Ever smoked marijuana & 192 & 91.4 & 25 & 96.2 & $0.703^{\mathrm{a}}$ \\
\hline \multicolumn{6}{|l|}{ Age first smoked } \\
\hline Mean $(95 \% \mathrm{Cl})$ & 14.8 & & 12.9 & & $<0.00 \mathrm{I}^{\mathrm{b}}$ \\
\hline Median (IQR) & $15(1$ & & 13( & & $0.00 I^{c}$ \\
\hline Marijuana use in past 90 days & $|7|$ & 89.5 & 24 & 96.0 & $0.480^{\mathrm{a}}$ \\
\hline \multicolumn{6}{|l|}{ Number of days smoked } \\
\hline Mean $(95 \% \mathrm{Cl})$ & 37.0 & & 52.6 & & $0.05^{\mathrm{b}}$ \\
\hline Median (IQR) & 20.0 & & 62.5 & & $0.09^{c}$ \\
\hline \multicolumn{6}{|l|}{ Daily smoker } \\
\hline No & 128 & 74.9 & 18 & 75.0 & \\
\hline Yes & 43 & 25.2 & 6 & 25.0 & $1.00^{\mathrm{a}}$ \\
\hline \multicolumn{6}{|l|}{ Alcohol use } \\
\hline Ever drank alcohol & 205 & 97.2 & 26 & 100.0 & $1.00^{\mathrm{a}}$ \\
\hline \multicolumn{6}{|l|}{ Age of first drink } \\
\hline Mean $(95 \% \mathrm{Cl})$ & 15.0 & & 14.1 & & $0.04^{b}$ \\
\hline Median (IQR) & $15(1$ & & 14 & & $0.06^{c}$ \\
\hline \multicolumn{6}{|l|}{ Age at first time getting drunk } \\
\hline Mean $(95 \% \mathrm{Cl})$ & 15.6 & & 14.6 & & $0.006^{\mathrm{b}}$ \\
\hline Median (IQR) & $16(1$ & & 15 & & $0.02^{c}$ \\
\hline \multicolumn{6}{|l|}{ Sum of two AUDIT questions } \\
\hline Mean $(95 \% \mathrm{Cl})$ & 3.34 & & 4.39 & & $<0.002^{\mathrm{b}}$ \\
\hline Median (IQR) & $3(2$, & & $4(3$ & & $0.004^{c}$ \\
\hline \multicolumn{6}{|c|}{ Problem level alcohol consumption } \\
\hline No & 121 & 59.2 & 9 & 34.6 & $0.02^{\mathrm{a}}$ \\
\hline Yes & 84 & 39.8 & 17 & 65.4 & \\
\hline
\end{tabular}

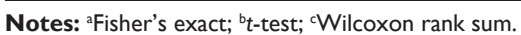

Abbreviations: $\mathrm{Cl}$, confidence interval; IQR, interquartile range; AUDIT, Alcohol Use Disorders Identification Test.

was $14.8(P<0.001)$. Marijuana use during the previous 90 days was ubiquitous: $89 \%$ and $96 \%$ of participants who never and ever joined gangs, respectively, reported smoking marijuana on at least 1 day (due in part to the study eligibility criteria) (Table 2). The statistical distributions of days smoked marijuana are U-shaped (Figure 1) for both groups, with the largest proportions of participants smoking either on 1 day or daily during the previous 3 months. Participants who never joined a gang smoked a mean of 37 days and a median of 20 days, whereas gang members smoked a mean of 53 days and a median of 63 days (Table 2), demonstrating significant differences in marijuana use between groups. The proportion of daily marijuana users, however, was comparable between groups ( $25 \%$ non-gang members and $25 \%$ gang members, $P=1.00$ ). The extreme values, rarely use and daily use, do not distinguish teens by gang membership. Figure 1 suggests that smoking at least 45-50 days was more common among gang members, and incremental increases in frequency of marijuana use increased the proportion of teens ever being in a gang. Although the sample size was small, these data show more variability in smoking frequency among youth with a history of joining gangs after a threshold of 45-50 days.

Nearly all participants ever drank alcohol, but the age of their first drink was significantly younger for gang members compared to nonmembers (14.1 years vs 15.0 years, respectively; $P=0.04$ ) (Table 2). Likewise, the age of the first time getting drunk was younger for gang members than nonmembers (14.6 years vs 15.6 years, respectively; $P=0.006$ ). Participants who had ever been gang members drank more often and in greater quantities as evidenced by the differences in the mean scores from the two AUDIT questions: youth who were never in gangs had a mean score of 3.35 as compared to 4.39 for gang members $(P<0.002)$. Youth who reported gang membership were nearly three times as likely to drink at a problem level $(65.4 \%$ vs $39.8 \%$; odds ratio $[\mathrm{OR}]=2.86,95 \%$ confidence interval $[\mathrm{CI}][1.22$, 6.71]) (not shown). 


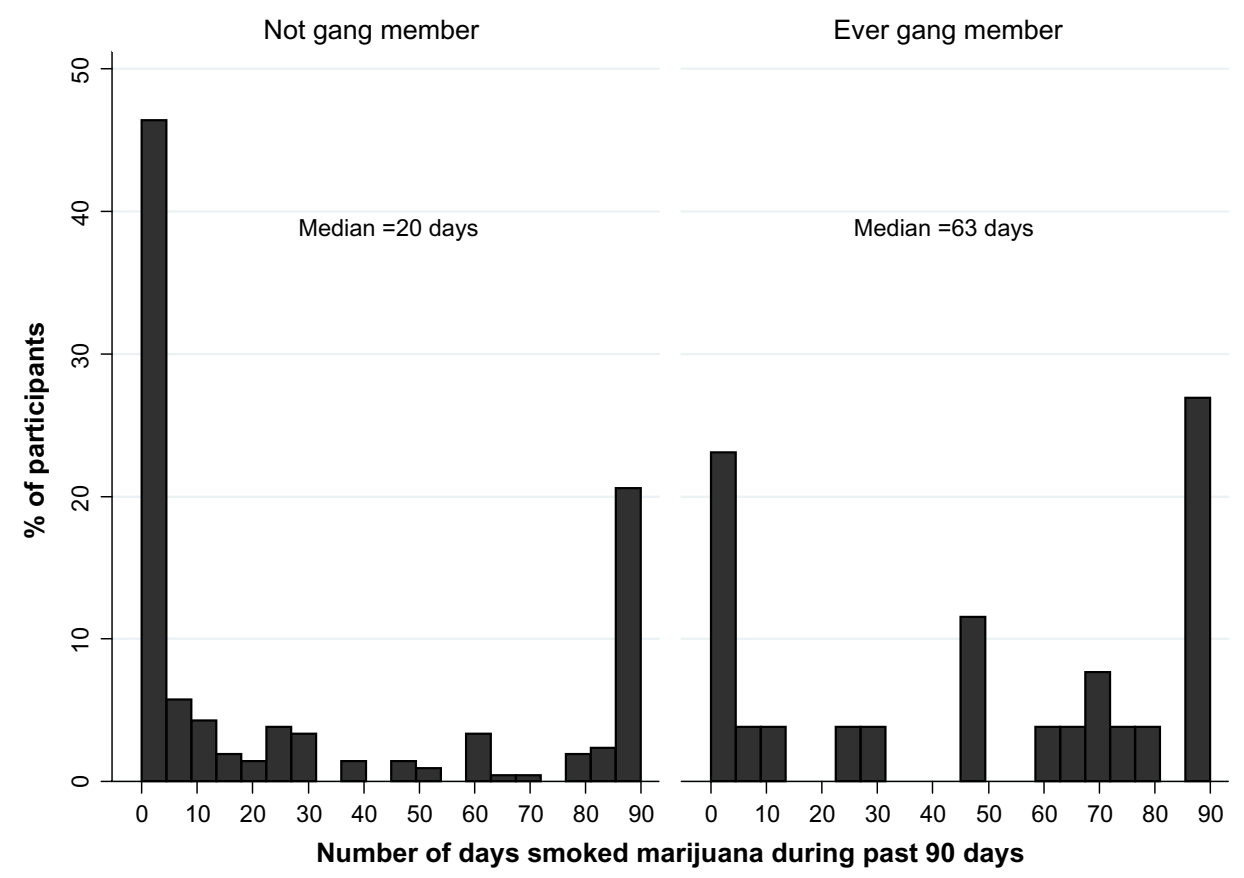

Figure I Distribution of the number of days smoked marijuana during past 90 days among participants who smoked at least I day, stratified by gang membership. Notes: Most participants smoked either on I day or daily. The median number of days was significantly higher among gang members. There was variability among gang members after a threshold of 45-50 days.

\section{Correlates of gang membership}

For each variable examined for correlation with gang membership in Table 3, all logistic models include terms for problem level drinking and frequent marijuana use (smoking 45 days of the past 90 days). Food insecurity, being a mother, and ever experiencing homelessness were not correlated with gang membership. However, adolescents in gangs were four times as likely to have run away from home $(50.0 \%$ vs $16.6 \%$; OR $=4.65$, $95 \% \mathrm{CI}[1.90,11.40])$, and twice as likely to have been arrested (61.5\% vs $30.3 \%$; OR $=2.61,95 \%$ CI $[1.05,6.47])$. In preliminary analysis, having concurrent sex partners and ever trading sex seemed to be correlated with gang membership, but the variables failed to reach statistical significance due to the small cell sizes after controlling for alcohol and drug use.

Although many young women in the full sample experienced emotional, sexual, or physical abuse (Table 3), the prevalence among those who were ever in gangs was markedly higher than those never in gangs. Approximately one-fifth (22\%) of non-gang members, as compared to $52 \%$ of past or present gang members, reported current emotional abuse from their main partner ( $\mathrm{OR}=3.55,95 \%$ CI $[1.44$, $8.72]$ ). Gang member youths were more than twice as likely to have ever experienced sexual abuse as non-gang members (38.5\% vs $18 \%$; OR $=2.60,95 \%$ CI $[1.06,6.40])$. Adolescents in gangs were seven times as likely to report physical abuse as participants who were not in gangs ( $69 \%$ vs $23 \%$; OR $=7.33$, 95\% CI $[2.90,18.53])$.
Gang members reported lower levels of social support for getting their needs met and less emotional support. Mean scores for emotional support were 21.6 and 18.9 for nonmembers and gang members, respectively (Table 3 ). For each unit increase in the emotional support score, the likelihood of being a gang member decreased $(\mathrm{OR}=0.89,95 \% \mathrm{CI}[0.81,0.97])$. In addition, gang members reported higher levels of depression ( mean $=11.7$ ) than nonmembers ( mean $=9.3$ ).

The mean scores for scales that assessed illegal behaviors for themselves and their peers were significantly higher among gang members (means $=3.5$ and 16.5, respectively) than youths who were never gang members (means $=1.2$ and 11.3, respectively). Perceived neighborhood violence during the previous 3 months that gang members reported (mean $=12.7$ ) was also significantly higher than nonmembers (mean $=7.9$ ). Table 3 also presents the prevalence and odds of reporting two of the 12 items in the scale that assessed neighborhood violence. Gang members were three times as likely to witness fights with weapons ( $\mathrm{OR}=3.06 ; 95 \% \mathrm{CI}$ $[1.15,8.11])$ and to report that a murder occurred in their neighborhood $(\mathrm{OR}=3.27,95 \% \mathrm{CI}[1.35,7.96])$.

\section{Discussion}

The Young Women's CoOp enrolled a sample of African American female adolescents from underserved neighborhoods in the southeastern US who were sexually active, used drugs and alcohol, and dropped out or considered dropping out 
Table 3 Correlates of gang membership among African American female adolescents, Raleigh and Durham NC, 2010-2012 (N=237)

\begin{tabular}{|c|c|c|c|c|c|c|c|c|c|}
\hline & \multicolumn{4}{|c|}{ Ever been in a gang } & \multirow{2}{*}{\multicolumn{2}{|c|}{ Overall sample }} & \multirow[t]{3}{*}{$\mathbf{O R}^{\mathrm{a}}$} & \multirow[t]{3}{*}{$95 \% \mathrm{Cl}$} & \multirow[t]{3}{*}{$P$-value } \\
\hline & \multicolumn{2}{|l|}{ No } & \multicolumn{2}{|l|}{ Yes } & & & & & \\
\hline & $(n=2 I I)$ & $\%$ & $(n=26)$ & $\%$ & $(n=237)$ & $\%$ & & & \\
\hline \multicolumn{10}{|l|}{ Sociodemographics } \\
\hline Food insecurity (ref: able to buy enough food) & 42 & 19.9 & 9 & 34.6 & 51 & 21.5 & 1.63 & $0.65,4.07$ & 0.293 \\
\hline Ever homeless (ref: never homeless) & 53 & 25.1 & II & 42.3 & 64 & 27.0 & 1.79 & $0.75,4.29$ & 0.188 \\
\hline Ever given birth (ref: never given birth) & 59 & 28.0 & 10 & 38.5 & 69 & 29.1 & 1.44 & $0.60,3.47$ & $0.4 \mid 4$ \\
\hline Ever run away from home (ref: never run away) & 35 & 16.6 & 13 & 50.0 & 48 & 20.3 & 4.65 & $1.90,11.40$ & 0.001 \\
\hline Ever arrested (ref: never arrested) & 64 & 30.3 & 16 & 61.5 & 80 & 33.8 & 2.61 & $1.05,6.47$ & 0.039 \\
\hline \multicolumn{10}{|l|}{ Hard drug use } \\
\hline Self-reported hard drug use (ref: no hard drug use) ${ }^{b}$ & 22 & 10.4 & 4 & 15.4 & 26 & 11.0 & 1.28 & $0.38,4.27$ & 0.693 \\
\hline \multicolumn{10}{|l|}{ Sexual behaviors } \\
\hline Age of first sex $\leq 13$ years (ref: age 14 or older) & 67 & 31.8 & 9 & 34.6 & 76 & 32.1 & 0.95 & $0.39,2.31$ & 0.901 \\
\hline Ever trade sex (ref: never trade sex) & 27 & 12.8 & 8 & 30.8 & 35 & 14.8 & 1.92 & $0.71,5.19$ & 0.198 \\
\hline Ever diagnosed with an STI (ref: never diagnosed) & 82 & 38.9 & 13 & 50.0 & 95 & 40.1 & 1.34 & $0.57,3.11$ & 0.502 \\
\hline $\begin{array}{l}\text { Concurrent sex partners ( } \geq 2 \text { partners in past } 30 \text { days) } \\
\text { (ref: one partner) }\end{array}$ & 39 & 18.6 & 10 & 38.5 & 49 & 20.8 & 2.24 & $0.91,5.53$ & 0.081 \\
\hline $\begin{array}{l}\text { Alcohol or drug use at last sex act (ref: no alcohol } \\
\text { and no drug use) }\end{array}$ & 62 & 29.4 & 9 & 34.6 & 71 & 30.0 & 0.62 & $0.23,1.63$ & 0.329 \\
\hline Condom used last sex (ref: condomless sex) & 111 & 52.6 & 11 & 42.3 & 122 & 51.5 & 0.70 & $0.30,1.63$ & 0.409 \\
\hline \multicolumn{10}{|l|}{ Abuse } \\
\hline Emotional abuse from main partner (ref: no abuse) & 40 & 21.9 & 13 & 52.0 & 53 & 25.5 & 3.55 & $1.44,8.72$ & 0.006 \\
\hline Sexual abuse in lifetime (ref: never sexually abused) & 37 & 17.6 & 10 & 38.5 & 47 & 19.9 & 2.60 & $1.06,6.40$ & 0.037 \\
\hline \multirow[t]{4}{*}{ Physical abuse in lifetime (ref: never physically abused) } & 49 & 23.3 & 18 & 69.2 & 67 & 28.4 & 7.33 & $2.90,18.53$ & $<0.001$ \\
\hline & \multicolumn{4}{|c|}{ Ever been in a gang } & \multicolumn{2}{|c|}{ Overall sample } & \multirow[t]{3}{*}{$\mathbf{O R}^{\mathrm{a}}$} & \multirow[t]{3}{*}{$(95 \% \mathrm{Cl})$} & \multirow[t]{3}{*}{$P$-value } \\
\hline & \multicolumn{2}{|c|}{ No $(n=2 \mid I)$} & \multicolumn{2}{|c|}{ Yes $(n=26)$} & \multicolumn{2}{|l|}{$(n=237)$} & & & \\
\hline & Mean & SD & Mean & SD & Mean & SD & & & \\
\hline \multicolumn{10}{|l|}{ Psychosocial scales } \\
\hline Material support score & 18.9 & 4.95 & 16.5 & 4.45 & 18.6 & 4.95 & 0.92 & $0.84,1.01$ & 0.066 \\
\hline Emotional support score & 21.6 & 4.74 & 18.9 & 4.64 & 21.3 & 4.8 & 0.89 & $0.8 \mathrm{I}, 0.97$ & 0.012 \\
\hline Depression score (CES-D) & 9.3 & 5.24 & 11.7 & 4.65 & 9.5 & 5.22 & 1.09 & $1.01,1.18$ & 0.036 \\
\hline Illegal behaviors & 1.2 & 1.44 & 3.5 & 2.32 & 1.5 & 1.71 & 1.78 & $1.40,2.26$ & $<0.001$ \\
\hline Peers' illegal behaviors & 11.3 & 7.40 & 16.5 & 10.72 & 11.8 & 7.98 & 1.06 & $1.01,1.12$ & 0.030 \\
\hline \multicolumn{10}{|l|}{ Violence } \\
\hline Perceived neighborhood violence & 7.9 & 7.60 & 12.7 & 10.28 & 8.5 & 8.05 & 1.05 & $1.00,1.10$ & 0.037 \\
\hline $\begin{array}{l}\text { Aware of murder in neighborhood } \\
\text { (ref: no awareness of a murder) }\end{array}$ & $\mathrm{N}=40$ & $19.1 \%$ & $\mathrm{~N}=13$ & $50.0 \%$ & $\mathrm{~N}=53$ & $22.5 \%$ & 3.27 & $1.35,7.96$ & 0.009 \\
\hline $\begin{array}{l}\text { Aware fights with weapons in neighborhood } \\
\text { (ref: no awareness of fights) }\end{array}$ & $N=99$ & $46.9 \%$ & $\mathrm{~N}=20$ & $76.9 \%$ & $N=119$ & $50.2 \%$ & 3.06 & $1.15,8.11$ & 0.025 \\
\hline
\end{tabular}

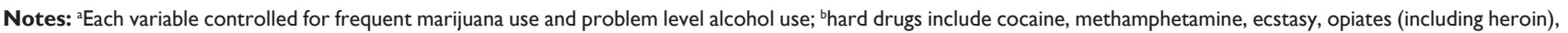
oxycodone or prescription medications.

Abbreviations: OR, odds ratio; Cl, confidence interval; STI, sexually transmitted infection; SD, standard deviation; CES-D, Center for Epidemiologic Studies Depression; ref, reference.

of school. Extant literature shows that each of these eligibility criteria is correlated with gang involvement and membership. Other studies of gang involvement among African American adolescents have been conducted in clinic settings,${ }^{28}$ detention centers, ${ }^{27}$ public schools, ${ }^{15,26}$ and alternative schools,${ }^{43}$ whereas this study recruited youth from communities and conducted the study in the community setting. In this cross-sectional analysis, we explored the variability of alcohol and marijuana use as it relates to gang membership and other correlates of gang membership. Gang members initiated smoking marijuana at a very young age. Participants, independent of gang membership, tended to not/rarely smoke or to smoke daily, but past or present gang members exhibited greater variability in smoking frequency after a threshold of 45 days of excess use during the previous 90 days (ie, $50 \%$ of the time). Gang members began drinking at a younger age, drank more frequently, and consumed more alcoholic drinks. Onset of drinking alcohol as an adolescent places youth at heightened risk of later alcohol misuse and dependence. ${ }^{44}$

Consistent with other research, ${ }^{45}$ the prevalence of violence and abuse in this sample was quite high overall and especially elevated among participants with gang 
membership experience. A quarter of the sample reported current emotional abuse, history of sexual or physical abuse, or awareness of a murder in their neighborhood. In contrast, half of those who were gang members reported emotional abuse and knowledge of a murder; 69\% reported past physical abuse. These young women seem to be at even higher risk and in need of intervention.

Some literature has concluded that female adolescents may gravitate toward gangs to get their material goods and needs met. ${ }^{43,46}$ These findings suggest that emotional support (people they feel comfortable talking to about important things) may be more important than social support. Our findings align with ample literature showing that lack of close bonds with family may prompt youth to join street gangs to gain a feeling of belonging. ${ }^{15,24,25,43,46}$ Furthermore, lack of family support and family problems were two of the most frequent reasons for dropping out of school, and gang members were more likely to have run away from home. These findings signal the urgent need for not only services that reach these adolescents at critical junctures before they may drop out of school but also programs that will help strengthen families living in strained and disadvantaged communities.

Although one-third of the sample became mothers at a young age, this finding was not associated with gang membership. Nonetheless, the risk of adolescent pregnancy cannot be ignored in this context, given that $73 \%$ of participants reported that they had a sex partner who was in a gang at least once. In a longitudinal study of Latinos 14-19 years of age in San Francisco, CA, survival analysis showed increased pregnancy risk among female participants whose male partners were gang members. ${ }^{47}$ Having a pregnant partner was associated with gang membership among detained male adolescents in Georgia. ${ }^{48}$ In this study, becoming a parent may have protected against gang membership, because maturation often occurs with becoming responsible for a baby. Similarly, qualitative research shows that pregnancy promotes female teens leaving gangs and friends from the street in general. ${ }^{31}$

Marijuana use was pervasive, with daily marijuana smokers accounting for $25 \%$ of all participants who reported smoking it. In addition, $43 \%$ of the study participants consumed excess amounts of alcohol. The extent of both alcohol and drug use reported by adolescents in our study could permanently impede their cognitive development because the brain is still developing during these years. ${ }^{49,50}$ Furthermore, substance use often affects motivation, thereby lowering the likelihood of reenrolling in school or technical school, obtaining a GED, and general academic achievement. ${ }^{51}$
These findings contribute to the growing evidence that professional intervention is needed regarding marijuana use among youths who drop out of school in communities with strong gang presence. ${ }^{49,50}$

This study has several limitations. The sample is not generalizable to African American or other ethnic/minority female adolescents in other cities or regions. This study purposely enrolled adolescents who drank alcohol, used drugs, and had sex without a condom to test the efficacy of an adaptation of the evidence-based Women's CoOp intervention. ${ }^{52}$ Other studies of gang involvement enroll targeted samples that are also not necessarily generalizable, such as youth in detention centers. ${ }^{27}$ This study fills a gap in the literature by enrolling youth who dropped out of high school or considered dropping out.

The study survey did not measure parental monitoring, which mitigates the likelihood of adolescents joining gangs ${ }^{30}$ and using drugs. ${ }^{51}$ At best, approximately half of the participants who dropped out did so because of family issues or a lack of family support, which may signal parental disengagement. Because the overall purpose of the study was to test the efficacy of a risk-reduction intervention rather than investigate gangs, the survey did not further explore feelings about gang membership such as perceived positive aspects. We also did not collect detailed information to assess participants' level of gang activity or commitment to gangs beyond crude measures of gang affiliation (52\%) and gang membership (11\%). Other research indicates that females involved with gangs may perform duties that may or may not be criminal activities such as providing alibis, holding guns, or holding drugs. ${ }^{14}$ Preliminary analyses (not reported here) examined correlates of gang affiliation; the results were comparable.

We cannot determine causality because the analysis was cross-sectional; other investigators have examined the reverse relationship by treating gang membership as the independent variable and drug use and risky sexual behaviors as outcomes. A qualitative study conducted by Miller with female youth in Columbus illustrates how females experience violence both before and after joining a gang. The teens "exchanged" known forms of victimization that occur in gangs for the random violence in their neighborhood. ${ }^{19}$ The diversity and volume of research in this area speak to the inherent relationships surrounding violence, sexual risk, and substance use in poor neighborhoods among racial/ethnic minorities with no sign of abating. ${ }^{24,33,53}$ While much of the research emphasizes criminal activity and severe violence usually experienced by males (eg, shooting), a gender-based theory and perspective 
has emerged for empirical research of females and gangs. ${ }^{13}$ Interventions for girls and female adolescents at risk of becoming involved with gangs should be developed with a gendered framework that includes violence and abuse. ${ }^{13}$

We recruited an acutely disadvantaged population of African American adolescent females from poor neighborhoods in Durham and Raleigh, NC, shaped by drug use, violence, poverty, and hardship. The prevalence of gang membership was relatively low (11\%); however, half of participants were affiliated, and most had family members in street gangs. The prevalence of gang exposure places adolescent females at risk of violence, and especially sexual exploitation and abuse if they join a gang. Many of these young African American women could benefit from a peerinspired intervention that focuses on their age, gender, and cultural context, with alternatives to gangs to steer them toward successful adulthood within their communities. Females in gangs require added attention in interventions because they are more likely to have substance abuse problems, severe violence and trauma experiences, and depression, and lack family support. In a joint report, both the CDC and the Department of Justice recognize gangs as a public health threat ${ }^{54}$ requiring a public health response..$^{55}$ It will take more than just one intervention to address these issues. A collaborative response is needed that includes structural and systems review to reach young people and offer alternatives in their communities.

\section{Acknowledgments}

The research described in this article was conducted with support from the Centers for Disease Control and Prevention Cooperative Agreement (5UR6PS000665; principal investigator: WM Wechsberg, PhD). We acknowledge Rachel Middlesteadt Ellerson's successful efforts to coordinate the project at two study locations, train and supervise study staff, and ensure that young women complete the study. We also wish to thank Alliance of AIDS Services - Carolina for its partnership in this project. The findings and conclusions in this report are those of the authors and do not necessarily represent the views of the Centers for Disease Control and Prevention.

\section{Disclosure}

The authors report no conflicts of interest in this work.

\section{References}

1. Adimora AA, Ramirez C, Schoenbach VJ, Cohen MS. Policies and politics that promote HIV infection in the Southern United States. AIDS. 2014;28(10):1393-1397.
2. Browne FA, Wechsberg WM, White VM, et al. The influence of social determinants on sexual risk among out-of-school African American female adolescents. Vulnerable Child Youth Stud. 2014;9(2): 139-150.

3. Raiford JL, Herbst JH, Carry M, Browne FA, Doherty I, Wechsberg WM Low prospects and high risk: structural determinants of health associated with sexual risk among young African American women residing in resource-poor communities in the south. Am J Community Psychol. 2014;54(3-4):243-250.

4. US Department of Education. The Condition of Education 2014 (NCES 2014-083). National Center for Education Statistics. Washington, DC: US Department of Education; 2014.

5. Reed E, Silverman JG, Welles SL, Santana MC, Missmer SA, Raj A Associations between perceptions and involvement in neighborhood violence and intimate partner violence perpetration among urban, African American men. J Community Health. 2009;34(4):328-335.

6. Floyd LJ, Brown Q. Attitudes toward and sexual partnerships with drug dealers among young adult African American females in socially disorganized communities. J Drug Issues. 2013;43(2):154-163.

7. Doherty IA, Schoenbach VJ, Adimora AA. Sexual mixing patterns and heterosexual HIV transmission among African Americans in the southeastern United States. J Acquir Immune Defic Syndr. 2009;52(1): 114-120.

8. Logan T, Walker R, Cole J. Silenced suffering: the need for a better understanding of partner sexual violence. Trauma Violence Abuse. 2013;16(2):111-135.

9. Logan T, Walker R, Cole J, Leukefeld C. Victimization and substance abuse among women: contributing factors, interventions, and implications. Rev Gen Psychol. 2002;6(4):325.

10. Sterk CE, Klein H, Elifson KW. Self-esteem and "at risk" women: determinants and relevance to sexual and HIV-related risk behaviors. Women Health. 2005;40(4):75-92.

11. Miller J. Getting Played: African American Girls, Urban Inequality, and Gendered Violence. New York, NY: NYU Press; 2008.

12. O’Brien K, Daffern M, Chu CM, Thomas SD. Youth gang affiliation, violence, and criminal activities: a review of motivational, risk, and protective factors. Aggress Violent Behav. 2013;18(4):417-425.

13. Miller J. One of the Guys: Girls, Gangs, and Gender. New York, NY: Oxford University Press; 2001.

14. Peterson D. Girlfriends, gun-holders, and ghetto-rats? Moving beyond narrow views of girls in gangs. In: Miller S, Leve LD, Kerig PK, editors. Delinquent Girls. Berlin: Springer; 2012:71-84.

15. De La Rue L, Espelage DL. Family and abuse characteristics of ganginvolved, pressured-to-join, and non-gang-involved girls. Psychol Violence. 2014;4(3):253-265.

16. Gover AR, Jennings WG, Tewksbury R. Adolescent male and female gang members' experiences with violent victimization, dating violence, and sexual assault. Am J Crim Justice. 2009;34(1-2):103-115.

17. Molidor CE. Female gang members: a profile of aggression and victimization. Soc Work. 1996;41(3):251-257.

18. Townsend M. Being Raped by a Gang is Normal - it's About Craving to be Accepted. The Guardian US edition; 2012. Available from: http:// www.theguardian.com/society/2012/feb/18/being-raped-by-gangnormal. Accessed July 1, 2015.

19. Miller J. Gender and victimization risk among young women in gangs. J Res Crime Delinq. 1998;35(4):429-453.

20. US Department of Justice; Office of Juvenile Justice and Delinquency Prevention. National Youth Gang Survey Analysis. Washington, DC: US. Department of Justice; Office of Juvenile Justice and Delinquency Prevention; 2014.

21. Chesney-Lind M. How can we prevent girls from joining gangs? In: Simon TR, Ritter NM, Mahendra RR, editors. Changing Course: Preventing Gang Membership. Washington DC: National Institute of Justice and Centers for Disease Control and Prevention; 2013: 121-133.

22. National Gang Intelligence Center, Federal Bureau of Investigation. 2011 National Gang Threat Assessment - Emerging Trends. Washington DC: National Gang Intelligence Center, Federal Bureau of Investigation; 2011. 
23. CDC. Gang homicides - Five US cities, 2003-2008. MMWR Morb Mortal Wkly Rep. 2012;61(03):46-51.

24. Harper GW, Robinson WL. Pathways to risk among inner-city AfricanAmerican adolescent females: the influence of gang membership. Am J Community Psychol. 1999;27(3):383-404.

25. Yoder KA, Whitbeck LB, Hoyt DR. Gang involvement and membership among homeless and runaway youth. Youth Soc. 2003;34(4): 441-467.

26. Gilman AB, Hill KG, Hawkins JD, Howell JC, Kosterman R. The developmental dynamics of joining a gang in adolescence: patterns and predictors of gang membership. J Res Adolesc. 2014;24(2):204-219.

27. Voisin DR, King KM, Diclemente RJ, Carry M. Correlates of gang involvement and health-related factors among African American females with a detention history. Child Youth Serv Rev. 2014;44:120-125.

28. Wingood GM, DiClemente RJ, Crosby R, Harrington K, Davies SL, Hook EW 3rd. Gang involvement and the health of African American female adolescents. Pediatrics. 2002;110(5):e57.

29. Dupéré V, Lacourse É, Willms JD, Vitaro F, Tremblay RE. Affiliation to youth gangs during adolescence: the interaction between childhood psychopathic tendencies and neighborhood disadvantage. $J$ Abnorm Child Psychol. 2007;35(6):1035-1045.

30. McCoy SI, Jewell NP, Hubbard A, et al. A trajectory analysis of alcohol and marijuana use among Latino adolescents in San Francisco, California. J Adolesc Health. 2010;47(6):564-574.

31. Fleisher MS, Krienert JL. Life-course events, social networks, and the emergence of violence among female gang members. $J$ Community Psychol. 2004;32(5):607-622.

32. Thornberry TP. Gangs and Delinquency in Developmental Perspective. Cambridge: Cambridge University Press; 2003.

33. Gilman AB, Hill KG, Hawkins JD. Long-term consequences of adolescent gang membership for adult functioning. Am J Public Health. 2014;104(5): 938-945.

34. Wechsberg, W. M., Novak, S. P., Doherty, I. A., Browne, F.A., Kline, T. L., Zule, W., Herbst, J. H. (2013). Preliminary Outcomes of the Young Women's CoOp on Sexual Risk Behaviors. Presented at 2013 APHA Annual Meeting, Boston, MA.

35. CDC. PS07-004: Adopting and Demonstrating the Adaptation of Prevention Techniques for Persons at Highest Risk of Acquiring or Transmitting Human Immunodeficiency Virus (ADAPT 2) - (UR6). Atlanta, GA: Centers for Disease Control and Prevention; 2007.

36. Sawyer-Kurian KM, Browne FA, Carney T, Petersen P, Wechsberg WM. Exploring the intersecting health risks of substance abuse, sexual risk, and violence for female South African teen dropouts. J Psychol Afr. 2011;21(1):15-25.

37. Wechsberg WM, Jones HE, Zule WA, et al. Methamphetamine ("tik") use and its association with condom use among out-of-school females in Cape Town, South Africa. Am J Drug Alcohol Abuse. 2010;36(4): 208-213.

38. Babor T, Biddle-Higgins JC, Saunders JB, Monteiro MG. AUDIT: The Alcohol Use Disorders Identification Test: Guidelines for Use in Primary Health Care. Geneva, Switzerland: World Health Organization; 2001.
39. Dunkle KL, Jewkes RK, Brown HC, et al. Prevalence and patterns of gender-based violence and revictimization among women attending antenatal clinics in Soweto, South Africa. Am J Epidemiol. 2004;160(3): 230-239.

40. Radloff LS. The CES-D scale a self-report depression scale for research in the general population. Appl Psychol Meas. 1977;1(3):385-401.

41. Aron A, Aron EN. Statistics for Psychology. Upper Saddle River, NJ: Prentice Hall; 1999.

42. Hosmer DW, Lemeshow S. Applied Logistic Regression. 2nd ed. New York, NY: Wiley; 2000.

43. Walker-Barnes CJ, Mason CA. Perceptions of risk factors for female gang involvement among African American and Hispanic women. Youth Soc. 2001;32(3):303-336.

44. Hawkins JD, Graham JW, Maguin E, Abbott R, Hill KG, Catalano RF. Exploring the effects of age of alcohol use initiation and psychosocial risk factors on subsequent alcohol misuse. J Stud Alcohol. 1997; 58(3): 280

45. Ulloa EC, Dyson RB, Wynes DD. Inter-partner violence in the context of gangs: a review. Aggress Violent Behav. 2012;17(5):397-404.

46. Bell KE. Gender and gangs: a quantitative comparison. Crime Delinq. 2009;55(3):363-387.

47. Minnis AM, Moore JG, Doherty IA, et al. Gang exposure and pregnancy incidence among female adolescents in San Francisco: evidence for the need to integrate reproductive health with violence prevention efforts. Am J Epidemiol. 2008;167(9):1102-1109.

48. Voisin DR, Salazar LF, Crosby R, DiClemente RJ, Yarber WL, Staples-Horne M. The association between gang involvement and sexual behaviours among detained adolescent males. Sex Transm Infect. 2004;80(6):440-442.

49. Squeglia LM, Jacobus J, Tapert SF. The influence of substance use on adolescent brain development. Clin EEG Neurosci. 2009;40(1): $31-38$.

50. van Holst RJ, Schilt T. Drug-related decrease in neuropsychological functions of abstinent drug users. Curr Drug Abuse Rev. 2011;4(1):42-56.

51. McCaffrey DF, Pacula RL, Han B, Ellickson P. Marijuana use and high school dropout: the influence of unobservables. Health Econ. 2010; 19(11):1281-1299.

52. Wechsberg WM, Lam WKK, Zule WA, Bobashev G. Efficacy of a woman-focused intervention to reduce HIV risk and increase selfsufficiency among African American crack abusers. Am J Public Health . 2004;94(7):1165-1173.

53. Voisin DR, Neilands TB. Community violence and health risk factors among adolescents on Chicago's southside: does gender matter? J Adolesc Health. 2010;46(6):600-602.

54. Simon TR, Ritter NM, Mahendra RR. Changing Course: Preventing Gang Membership. Washington DC: National Institute of Justice and Centers for Disease Control and Prevention; 2013.

55. McDaniel DD. Risk and protective factors associated with gang affiliation among high-risk youth: a public health approach. Inj Prev. 2012;18:253-258.
Substance Abuse and Rehabilitation

\section{Publish your work in this journal}

Substance Abuse and Rehabilitation is an international, peer-reviewed, open access journal publishing original research, case reports, editorials, reviews and commentaries on all areas of addiction and substance abuse and options for treatment and rehabilitation. The manuscript management system is completely online and includes a very quick and fair

\section{Dovepress}

peer-review system. Visit http://www.dovepress.com/testimonials.php to read real quotes from published authors. 